\title{
Colonic duplication with heterotopy of gastric
}

\section{mucosa}
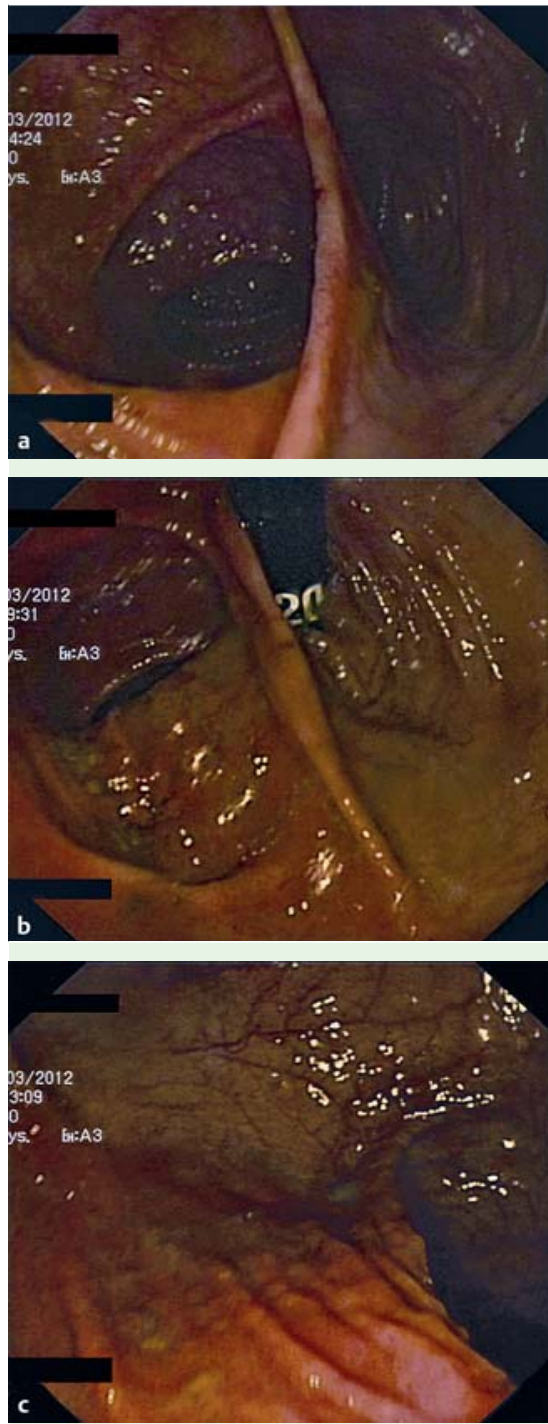

Fig. 1 Colonic duplication seen in endoscopy in a 48-year-old man with frequent motions. a Distal double lumen of descending colon. b Proximal double lumen of transverse colon in retroflexion. c Macroscopic view of gastric heterotopy in duplicated colon.

Gastrointestinal duplications are rare congenital anomalies, occurring in 1/5000 livebirths [1,2]. However, colonic duplications are extremely rare with only $7 \%$ of duplications involving the colon [3]. Heterotopy of gastric mucosa is a congenital lesion that often accompanies

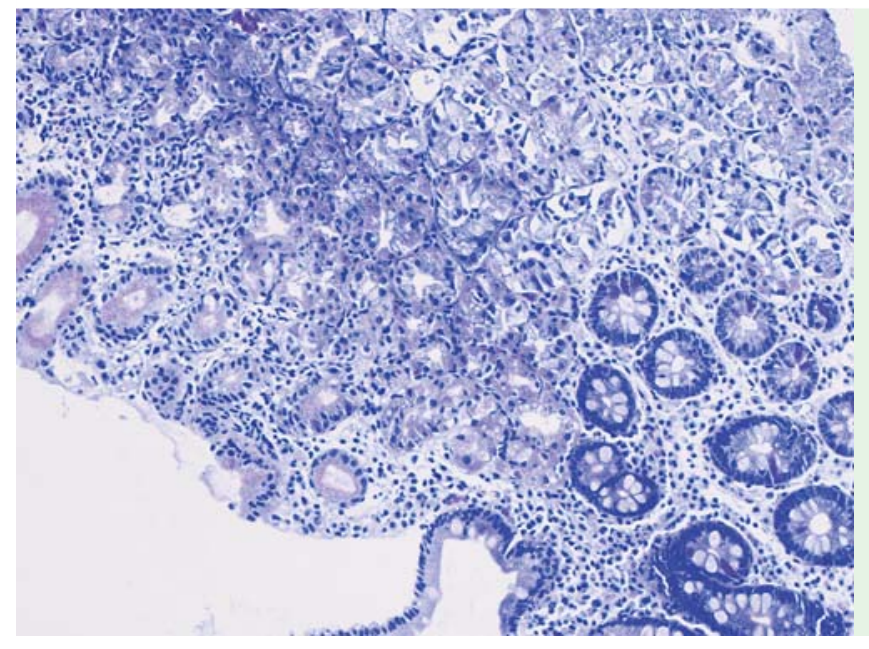

Fig. 2 Microscopic view of gastric heterotopy in the colon. Numerous fundic glands are present in deeper portion of the mucosa, with gastric foveolae on the surface. Some intestinal crypts, with Paneth's cells typical of the proximal colon, are visible in the lower right portion of the photomicrograph (hematoxylin and eosin, original magnification $\times 100)$.

intestinal duplication [4]. In the case of symptomatic duplications, surgery is the treatment of choice, especially when complicated by ileus or hemorrhage [5]. Here we present an unusual case of largebowel duplication in a patient with chronic diarrhea.

A 48-year-old man having four to six motions daily was seen in the outpatients clinic. On examination, infection was excluded and Crohn's disease was suspected. The patient was referred to the gastroenterology department. Routine blood tests did not reveal any abnormalities. Esophagogastroduodenoscopy showed longitudinal ulceration at the duodenal bulb. Histological examination revealed chronic unspecific duodenitis with foci of granulation tissue but no granulomas. Following these investigations, a colonoscopy was done, which revealed an unusual presentation of the large intestine. A structure seen at the outer edge of the anus seemed like the orifice of a perianal fistula. At the start of the procedure, the colonoscope was inserted into the descending colon, where a double distal lumen was observed ( $\bullet$ Fig. 1 a). The colonoscope was inserted first into the right lumen and, then into the left one, and each time it reached the cecum and terminal ileum. In the cecum, the scope was retroflected, revealing a proximal double lumen ( $\bullet$ Fig. 1 b). Along with colonic duplication, mucosal changes including edema, nodulation, and salmon-like color were also noted ( $\bullet$ Fig. 1 c). Microscopically, extensive heterotopy of the gastric mucosa was observed ( $\mathbf{F i g . 2}$ ). To identify precisely the extent of the duplication, barium enema was carried out (๑ Fig.3). As a perianal fistula was suspected, transrectal ultrasound examination was also done ( Fig. 4). Prior to this report, a likely association between Crohn's disease and large-bowel duplication has not been described.

Endoscopy_UCTN_Code_CCL_1AD_2AJ

Competing interests: None

\section{A. Madro ${ }^{1}$, K. Celinski ${ }^{1}$, B. Prozorow- Krol $^{1}$, C. T. Lozowski ${ }^{1}$, L. Buk ${ }^{2}$, J. Swatek ${ }^{3}$, J. Pilat ${ }^{4}$, M. Slomka ${ }^{1}$}

${ }^{1}$ Department of Gastroenterology with Endoscopic Unit, Medical University, Lublin, Poland

${ }^{2}$ Department of Radiology and Telemedicine, Medical University, Lublin, Poland ${ }^{3}$ Department of Clinical Pathomorphology, Medical University, Lublin, Poland

${ }^{4}$ Department of Surgery, Transplantology and Clinical Nutrition, Medical University, Lublin, Poland 


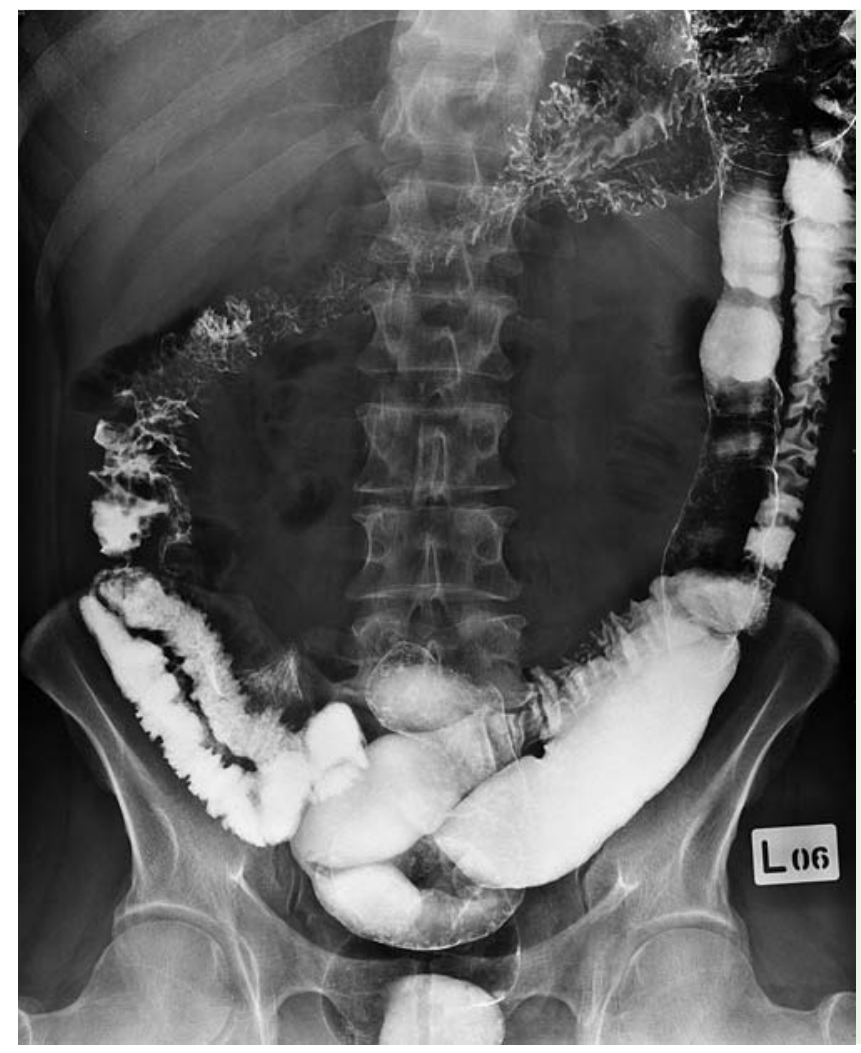

\section{References}

1 Mourra N, Chafai N, Bessound B et al. Colorectal duplication in adults: report of seven cases and review of the literature. J Clin Pathol 2010; 63: 1080-1083

2 O'Neil J, Rowe M. Duplications of the gastrointestinal tract. In: Rowe MI, O'Neill JA, Grosfeld JL et al., eds. Essentials of pediatric surgery. St Louis: Mosby Yearbook; 1995: 520-525

3 Fotiadis C, Genetzakis M, Papandreou I et al. Colonic duplication in adults: Report of two
Fig. 3 Colonic duplication seen on barium enema film. The duplicated bowel stretched from one-third of the distal colon as far as the flexure of the descending colon and the sigmoid colon.

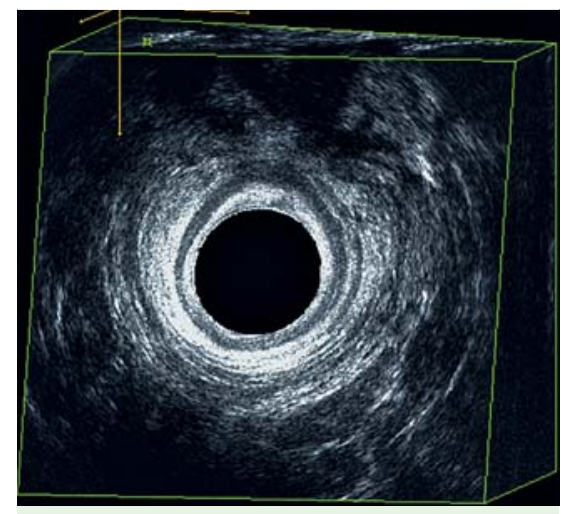

Fig.4 Transrectal ultrasound examination showing the perianal fistula.

\section{Bibliography}

Dol http://dx.doi.org/

10.1055/s-0032-1326463

Endoscopy 2013; 45: E153-E154

(c) Georg Thieme Verlag KG

Stuttgart · New York

ISSN 0013-726X

\section{Corresponding author}

\section{A. Madro}

Department of Gastroenterology with Endoscopic Unit Medical University

cases presenting with rectal bleeding. World J Gastroenterol 2005; 28: 5072 - 5074

4 Ben-Brahim E, Jouini R, Aboulkacem $S$ et al. Gastric heterotopias: clinical and histological study of 12 cases. Tunis Med 2011; 89: 935-939

5 Holocomb GW, Gheissari A, O'Neill JA Jr. Surgical management of alimentary tract duplications. J Pediatr Surg 2003; 209: 167-172
Lublin

Poland

Fax: +48817244535

agnieszka.madro@wp.pl 